\title{
Using Technology To Leverage Your Lectures' Stickiness
}

Chula G. King, (E-mail: cking@uwf.edu), University of West Florida

\begin{abstract}
Increasingly, universities are scrambling to take advantage of online technologies. This article describes one such technology that can be used to capture the video and audio of a PowerPoint lecture. The specific technology is a software program called Camtasia. With Camtasia one can simultaneously capture in a movie file everything that is occurring on a computer screen along with the audio narration. Once captured, the video and audio can be produced as a streaming video and uploaded to a web server for online viewing.
\end{abstract}

\section{Introduction}

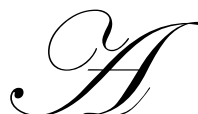

significant disconnect exists today between the expertise of faculty in subject matter delivery, and student expectations of methods of subject matter delivery. This disconnect occurs in part because of the general tendency of faculty to teach as they were taught. Most business faculty today received their formal education at a time when e-learning technologies were either in their infancy or non-existent. Because of this, faculty possess varying degrees of comfort in utilizing technology based strategies to improve their students' educational experience. Most business students today, however, accept computer and Internet technologies as a normal component of every day life. Thus, the student demand for educational alternatives to the physical classroom is growing. The disconnect between faculty expertise and student demand has made it possible for forprofit companies such as The University of Phoenix and Capella University to gain an expanding share of the business education market.

Increasingly, colleges and universities are scrambling to take advantage of technology based instruction (TBI) to augment and deliver courses that ten years ago were confined to the realm of a physical classroom. The next section of this paper presents an overview of the general issues faculty face in planning, creating, and executing TBI. This is followed by a discussion of TBI issues related to regional and national accreditations. Next, the paper presents information on streaming media technologies that anyone who uses PowerPoint can easily take advantage of to either enhance the educational experience of face-to-face students, or create a virtual classroom where instruction can take place anytime, anywhere. The paper then offers actual examples of how these technologies are being used in both accounting and general business courses. Finally, concluding comments are offered.

\section{Faculty Issues Related to Technology Based Instruction}

"Distance education is planned learning that normally occurs in a different place from teaching and as a result requires special techniques of course design, special instructional techniques, special methods of communication by electronic and other technology, as well as special organizational and administrative arrangements" (Moore \& Kearsley, 1996, page 2). When faculty embark on the creation of either course components or full courses that will be delivered electronically, they face a number of issues. These issues include those related to instruction, training, compensation, and intellectual property.

Motivation is one of the key ingredients to successful learning. This is true for both face-to-face courses and TBI. In a face-to-face course, the instructor relies on a collective audience, eye contact, a chalkboard, auditory communication, and his/her presence to enhance student motivation (Tesone et al., 2003). With the exception of eye contact, these features are available in an online environment. However, they must be augmented with technology. 
For example, the collective audience is present in discussion forums and online chats. PowerPoint and streaming media replace the chalkboard and auditory communication. The instructor's presence is felt in discussion forums, chat rooms, e-mail, and online office hours. According to Allen (2003, page 157), instructors utilize the following seven items to motivate online learners:

- $\quad$ Build on anticipated outcomes.

- $\quad$ Put the learner at risk.

- $\quad$ Select the right content for each learner.

- Use an appealing context.

- $\quad$ Have the learner perform multistep tasks.

- $\quad$ Provide intrinsic feedback.

- $\quad$ Delay judgment.

Faculty who have traditionally taught in a face-to-face environment often find the lack of experience in using technology to be a major road block in developing online course components or entire online courses. To be successful in the online environment, faculty should be able to use technology to develop appropriate interaction and instructional materials (Gunawardena, 1990). In addition, they should be able to apply the technologies that are most suitable to the course's specific student learning outcomes (Rockwell et al., 2000). For example, faculty should have some knowledge of an HTML authoring program such as Macromedia Dreamweaver or Adobe GoLive, and also be able to take advantage of multiple technologies to enhance the learning environment. Where meaningful, faculty should be able to incorporate streaming media or effectively designed PowerPoint presentations into the course. Faculty should understand that students in an online environment increasingly expect real-time responses to questions or issues. They should therefore explicitly set response guidelines and stick to those guidelines. In doing so, however, faculty should realize that meaningful feedback is essential to a well designed technology based course.

According to the AAUP's Statement on Distance Education (2001, page 180), “adequate preparation for a distance-education course ... requires considerable time and effort for the creation or adaptation of materials for the new media, and for the planning of assignments, evaluations, and other course materials and their distribution. The instructor will therefore need to have adequate time to prepare such materials and to become sufficiently familiar with the technologies of instruction prior to delivery of the course." In addition to this, faculty teaching an online class generally find that it involves more time and interaction with students than a face-to-face class. In fact, Tomei (2004) found that online teaching requires a minimum of $20 \%$ more time than traditional instruction, and that the majority of the time is spent in presenting instructional content. Others feel that the number is closer to $25 \%$ (Young, 2002). Both the development and teaching of an online course raise issues to do with the compensation of the faculty member. Schifter (2004) found that the most often cited method of compensation for online course development is the purchase of software, followed by the purchase of computer equipment, and the coverage of the costs of campus service units. Faculty overload pay is provided only $34 \%$ of the time, and faculty release time is granted only $18 \%$ of the time. In the same study, Schifter (2004) found comparable compensation schemes related to the actual teaching of the online course.

When a faculty member develops an online course or an online component of a face-to-face course, the significant question of who owns the intellectual property rights arises. The intellectual property rights relate to ownership of the actual content, control over how and when the content can be used, control over the copyright(s), control over the course distribution, compensation for sale or distribution of the course, and the relationship between faculty compensation to develop the online course and the intellectual property rights. The assignment of rights is generally part of a university's collective bargaining agreement or university policies. Carnevale (2000) describes a model intellectual property policy as one where: 
- $\quad$ Faculty members are paid to develop online courses.

- Faculty members own the material in the courses they develop, and control how and when that material can be used.

- $\quad$ The institution controls the copyrights of the online courses and manages the courses' distribution.

- In return for giving up the copyright on a course, a faculty member receives one-third of the revenue whenever a business or other institution purchases the rights to use the course.

Unfortunately, many universities have much more restrictive intellectual property policies.

\section{Accreditation Issues}

Technology based instruction is becoming an increasingly important component of educational programs. As this is occurring, significant pressures are being felt by accreditation agencies to ensure that the quality of the higher education experience is present in both traditional instruction and technology based instruction. Eaton (2000) describes institutional autonomy, collegiality and shared governance, intellectual and academic authority of faculty, the degree conferred, general education, and site-based education and a community of learning as core academic values sustaining regional accreditation. These core values, however, need to be equally applicable to both the traditional educational environment and the online environment. This places the onus on accreditors to define the similarities in and the differences between the two environments. Accreditors need to ensure that student learning outcomes are central to these efforts. Finally, accreditors need to be ever cognizant of the growing public concerns over educational quality and legislative concerns over accountability.

Both regional and national accreditation agencies have begun the task of embracing technology based instruction by moving away from content based assessment and focusing instead on student learning outcome assessment. The view is that learning outcomes should be the same, regardless of the way the course is delivered. Therefore, colleges and universities are being required to focus on those student learning outcomes and reliable means of measuring the outcomes.

The academic challenges resulting from the continued movement to technology based instruction are profound. However, Eaton (2001, page 12) notes that many accreditors have chosen to apply existing standards for face-to-face instruction to distance learning. The rationale in doing this is that expectations of quality should transcend the means of course delivery. Eaton (2001, page 13), however, suggests that in the future, institutions can expect accreditors to:

- $\quad$ Identify features which make distance learning delivery different from traditional delivery.

- Modify accreditation guidelines, policies or standards to ensure quality in the distinctive online environment.

- Focus additional attention on student achievement and learning outcomes in the context of distance learning.

- Work with government to adjust current policy understandings about the use of federal and state funds and about quality assurance in the distance learning environment.

- $\quad$ Assume more responsibility for addressing public concerns about the quality of higher education within the ever expanding environment of technology based instruction.

\section{Streaming Media Technologies}

Streaming media is a technology that allows on-demand electronic distribution and viewing of audio, video, and multimedia. In streaming media, the audio, video, and multimedia are simultaneously transferred by a server application so that they are received and displayed in a continuous, real-time stream by a client application. The streaming media begins playing as soon as enough data is received and stored in the client application buffer. Unlike other applications, however, the streamed file is simultaneously downloaded and viewed, but leaves behind no physical file on the viewer's machine. 
Audio and video files tend to be quite large. When they are viewed online, the size becomes significant because of the Internet connection speed or available network bandwidth. This is so even with a broadband connection. Therefore, some type of compression technology is required to make the media streaming manageable. This technology is known as codec, short for compressor/decompressor. When the audio, video, or other multimedia is transmitted from a server to the client, a codec is used to compress the media on the sending end, and decompress it on the receiving end.

A number of commercial software packages are available that allow one to add audio to a PowerPoint presentation, and then publish the product as streaming media. Once published, the streaming media is uploaded to a web server for online viewing. Examples of the software include Microsoft Producer, RoboPresenter, RoboDemo, and Camtasia Studio.

Microsoft Producer is a free plug-in to PowerPoint. With Producer, one can edit PowerPoint slides, capture the slide animation, synchronize the slides with audio, and publish the finished product as a compressed Windows Media file. RoboPresenter is also a PowerPoint plug-in. Unlike Microsoft Producer, RoboPresenter must be purchased. It allows one to convert a PowerPoint presentation to the Flash format. The Flash presentation can include audio, interactivity, simulations, and animation. RoboDemo allows one to create interactive demonstrations and software simulations in the Flash format. The on-screen actions and mouse movements are captured, along with the audio. Camtasia Studio, the final product, is discussed in the next section.

\section{Using Camtasia Studio}

As previously mentioned, a number of software packages are available to combine PowerPoint presentations and narration. In this section of the paper, the focus is on Camtasia Studio (Camtasia), and two actual applications. One application involves a totally online class, and the other involves a traditional face-to-face class. The totally online class is an MBA foundation course bridging accounting concepts with finance applications. The face-to-face class is Intermediate Accounting I.

Camtasia (TechSmith, 2004) is a video production software package. With the recorder, one records onscreen activity, real-time effects such as object highlighting, text, graphic, and image annotations, desktop drawings, and zoom-ins and outs. In addition, one narrates the video either during or after the recording.

Consider a lecture centered around a PowerPoint presentation. The laptop is connected to a projector. A standard computer microphone is plugged into the laptop. The computer is turned on, and Camtasia recorder is opened in the pause mode. The PowerPoint slide show is launched. Using a hotkey, the presenter begins the recording, and proceeds to deliver the lecture. Everything that is projected to the class is being recorded. Simultaneously, everything that the presenter is saying is being recorded. During the lecture, the presenter uses a hotkey to pause and re-start the recording without having to close or minimize the slide show. When the lecture is finished, the presenter uses another hotkey to stop the recording. In a nutshell, the presenter has just captured his or her entire lecture.

The initial recording is saved as an Audio/Video Interleave (AVI) file. This Microsoft defined file format is the most often used audio/video format in the Windows environment. It is not compressed with one specific codec. Rather, it is compressed or decompressed with many available codecs. From the initial recording, one can edit the audio and/or the video portion and then produce a movie in a number of different streaming formats. The available formats include Flash (*.SWF), Microsoft Windows Media (*.WMV), RealNetworks RealMedia (*.RM), and Apple QuickTime (*.MOV). Each of these formats uses a free, readily available player. The production setup for each of these streaming formats provides a number of audio and video compression options, allowing one to find the best mix of file compression and desired quality. An example of the impact of compression on file size involves a 50-minute recording of a PowerPoint lecture. The initial AVI file was 155,119 KB in size. When produced as a WMV file, the file was reduced in size to $9,521 \mathrm{~KB}, 8 \%$ of its original size. With this small size, the file was easily uploaded to a web server for online viewing. The student, using a standard dial-up connection, only had to wait three-seconds for the WMV file to begin playing. 
An often heard concern about a totally online class is that the students do not have the opportunity to hear the professor's lecture. Camtasia solves this problem. With a little bit of forethought, the professor is able to create media-rich lectures, and publish the movie to a web server for student viewing. Unlike a traditional lecture that occurs in a defined class time period and often covers multiple topics, a digital lecture is easily broken up into smaller modules. For example, time value of money is one of the topics covered in finance. A typical lecture on time value of money includes a general discussion of the time value of money concepts, followed by discussions on the specific components. A digital lecture on time value of money could be broken up into six different PowerPoint modules: (1) Overview of time value of money concepts; (2) present value of a single sum, with examples; (3) future value of a single sum, with examples; (4) present value of an annuity, with examples; (5) future value of an annuity, with examples; and (6) putting it all together to solve problems. The drawing and animation features of PowerPoint are used to illustrate the derivation and use of the time value of money formulas, the use of a financial calculator to solve problems, the use of time value of money tables to solve problems, and the differences between an ordinary annuity and an annuity due. The benefit of breaking the lecture up into well defined modules is that the student has available six smaller streaming videos lasting approximately 15 to 20 minutes each instead of one large streaming video lasting up to two hours. In addition, the student can more easily view all or some of the videos multiple times. The professor is able to easily simulate a face-to-face lecture while sitting at his or her desk.

Camtasia can also be used to capture a live lecture in a face-to-face class. For example, consider a PowerPoint lecture in Intermediate Accounting dealing with the overview of the accounting process. Utilizing the drawing and animation features of PowerPoint, the professor simulates what would be written on a chalkboard. In PowerPoint, the discussion of a specific item such as an accrual based adjusting entry is easily bulleted and illustrated in much the same way as it is bulleted and illustrated on a chalkboard. During the PowerPoint lecture, Camtasia records not only all screen activity, but also everything that the professor says during the lecture. If the professor wants to introduce a simulation of writing on the chalkboard, he or she can use a product such as PC Notes Taker or a tablet PC and capture everything that is written on the screen along with the narration. After the lecture is recorded, the professor produces it in one of the streaming video formats offered by Camtasia, and publishes the lecture for students to view online. This is helpful to students who miss the lecture and also students who want to review what was done in class.

\section{Concluding Comments}

Students are increasingly expecting educational alternatives to the traditional face-to-face lecture. This places more and more pressure on faculty members to re-think not only their roles as professors, but also the most effective means of delivering their lecture material. Whether the class is taught totally face-to-face, with a blend of traditional and electronic delivery, or totally online, the professor can use technology to leverage the stickiness of the lectures. One such example of this is the conversion of a PowerPoint presentation into streaming media. When uploaded to a web server, the streaming media is available for online viewing.

Faculty who are interested in pursuing this use of technology need to become proficient with the media-rich features of PowerPoint as well as a software package such as Camtasia that is capable of screen and audio capture, and streaming media production. In addition, they need to be aware of the added time involved in developing and producing the streaming media. They should also be knowledgeable of their university's intellectual property policies.

The picture of the classroom of tomorrow is anything but clear. What is clear, however, is that student expectation and marketplace demand will ultimately shape that classroom. To be successful in future, faculty will need to embrace technology as a powerful tool that can enhance the student's learning experience.

\section{References}

1. Allen, M. (2003). Michael Allen's guide to e-Learning. Hoboken, NJ: John Wiley \& Sons, Inc.

2. American Association of University Professors (AAUP). (2001). Statement on distance education. Policy documents \& reports, 9th Ed. Washington, D.C.: American Association of University Professors. 
179-181.

3. Carnevale, D. (November 22, 2000). New intellectual-property policy at Stevens is a model, both sides agree. The chronicle of higher education. [Online]. Available: http://chronicle.com/free/2000/11/2000112201u.htm.

4. Eaton, J. (2000). Core academic values, quality and regional accreditation. Council for higher education accreditation. CHEA Monograph Series. Washington, D.C. [Online] Available: http://www.chea.org/Research/core-values.cfm.

5. _ (2001). Distance learning: academic and political challenges for higher education accreditation. Council for higher education accreditation. CHEA Monograph Series. [Online]. Available: http://www.chea.org/commentary/distance-learning/chea_dis_learning.pdf.

6. Gunwardena, C. (1990). Integrating telecommunications to reach distance learners. The American journal of distance education, 4:3. 42-46.

7. Moore, M., \& Kearsley, G. (1996). Distance education: a systems view. California: Wadsworth Publishing Company.

8. Rockwell, K., Schauer, J., Fritz, S., \& Marx, D. (Summer 2000) Faculty education, assistance and support needed to deliver education via distance. Online journal of distance learning administration, 3:2. [Online] Available: http://www.westga.edu/ distance/rockwell32.html.

9. Schifter, C. (Spring 2004). Compensation models in distance education: national survey questionnaire revisited. Online journal of distance learning administration, 7:1. [Online] Available: http://www.westga.edu/\%7Edistance/ojdla/spring71/schifter71.html.

10. TechSmith. (2004). Camtasia Studio. [Online] Available: http://www.techsmith.com/products/studio/default.asp.

11. Tesone, D., Alexakis, G. \& Platt, A. (Winter 2003). Distance learning programs for non-traditional and traditional students in the business disciplines. Online journal of distance learning administration, 6:4 [Online] Available: http://www.westga.edu/ distance/ojdla/winter64/tesone64.html.

12. Tomei, L. (January 2004). The impact of online teaching on faculty load. International journal of instructional technology and distance learning, 1:1. [Online] Available: http://itdl.org/journal/Jan_04/article04.htm.

13. Young, J. (May 31, 2002). The 24-hour professor. The Chronicle of Higher Education. [Online] Available: http://chronicle.com/free/v48/i38/38a03101.htm. 